\title{
COMUNICAÇÕES
}

\section{TRATAMENTO CONTÁBIL DO CÂMBIO FLUTUANTE NO BRASIL - UMA PROPOSTA FRENTE À GRANDE VOLATILIDADE 2001/2002*}

\author{
Natan Szuster \\ Professor Titular da Universidade Federal do Rio de Janeiro - UFRJ \\ Professor Adjunto da Universidade do Estado do Rio de Janeiro - UERJ \\ E-mail: szuster@iis.com.br \\ Fortunee Szuster \\ Professora da FGV/RJ \\ Professora da PUC/RJ \\ Mestre em Ciências pela UERJ
}

RESUMO

Nos anos de 2001 e 2002, a existência de elevações transitórias no valor do dólar frente ao real, posteriormente revertidas, acarretaram a geração de Demonstrações Contábeis distorcidas para empresas brasileiras que possuíam ativos ou passivos com cláusula de variação cambial, gerando uma grande volatilidade nos resultados apresentados.

O presente trabalho apresenta uma proposta de adoção de um conceito denominado de "Dólar Justo", calculado com base na ciência econômica através da Teoria da Paridade Cambial , utilizando a base de cálculo desenvolvido pelo Banco Mundial. Esse tratamento possibilitaria a contabilização das variações monetárias dos ativos e passivos de longo prazo com cláusula de variação cambial, de forma linear, evitando a apuração de lucros e prejuízos temporários.

O parâmetro para avaliação patrimonial não considera como referencial único a taxa corrente do dólar, mas um valor relacionado ao montante que será em perspectiva utilizado, na data de realização dos elementos patrimoniais.

A metodologia de cálculo e a forma de obtenção dos valores é demonstrada e exemplificada. São abordadas diversas alternativas para evidenciação e contabilização da diferença entre o valor do dólar
ABSTRACT

In 2001 and 2002, the existence of transitory elevations in the value of the dollar as opposed to the real, which were reverted later on, caused the creation of distorted Financial Statements for Brazilian companies that owned assets or liabilities with an exchange variance clause, generating a high level of volatility in the presented results.

This study presents a proposal for the adoption of a concept called "Fair Dollar", calculated on an economic base by means of the Exchange Parity Theory, using the calculation base that was developed by the World Bank. This treatment would allow for the accounting treatment of monetary variations in long-term assets and liabilities with an exchange variance clause in a linear way, avoiding the determination of temporary gains and losses.

The parameter for equity valuation does not consider the current dollar rate as the only reference base, but a value linked up with the amount that will be used in perspective, at the realization date of the equity elements.

The methodology for calculating and obtaining the values is demonstrated and exemplified. Various alternatives are approached for the disclosure and accounting treatment of the difference between the

*originalmente publicado no IOB - nº 8/2003 - Caderno Temática Contábil 
efetivo na data do Balanço e o denominado "DólarJusto".

O objetivo do artigo é ampliar o debate sobre os efeitos para a contabilidade decorrentes da adoção do câmbio flutuante sugerindo uma alternativa de mudança . Essa deverá ser bem avaliada quanto a viabilidade prática de mudança pois propicia um aumento da qualidade das Demonstrações Contábeis mas irá ensejar uma alteração na atual estrutura conceitual básica da contabilidade.

Palavras-chave:demonstrações contábeis, contabilização das variações cambiais, tratamento da flutuação do câmbio. actual value of the dollar at the date of the Balance Sheet and the so-called "Fair Dollar".

This article aims to broaden the debate about the effects of the adoption of the floating exchange rate for accounting, suggesting an alternative for change. This alternative must be evaluated carefully with respect to the practical viability of change, since it will not only signify an increase in the quality of Financial Statements but also a change in the current basic conceptual structure of accounting.

Keywords: financial statements, accounting treatment of exchange variance, treatment of exchange flotation. 


\section{INTRODUÇÃO}

No artigo "Variações Cambiais: Contabilidade e Fisco", publicado no Boletim Temática Contábil IOB nํำ 08 em Fevereiro de 2000, o professor Eliseu Martins sugere serem necessários maiores debates sobre os efeitos para a contabilidade decorrentes da adoção do câmbio flutuante e desenvolve questionamentos ao procedimento tradicional, apresentando inclusive a posição internacional de reconhecimento de determinados valores como ajuste ao patrimônio líquido.

Segundo o professor Mário Henrique Simonsen o regime de taxas de câmbio flutuantes gera muitas vantagens mas também muitas limitações. A desvantagem fundamental detecta-se na própria denominação as taxas flutuam, e as flutuações de curto prazo não necessariamente apontam para as tendências de longo prazo. Geram-se, assim valorizações e desvantagens transitórias, incapazes de resistir ao longo do tempo. O mal dessas oscilações é que as valorizações transitórias sucateiam indústrias de exportação inutilmente submetendo a indústria local a uma competição externa predatória. As desvalorizações transitórias funcionam no sentido inverso. Comprimem os salários reais e iludem a economia com uma competitividade que realmente vai acima de seu limite."

Os efeitos do tratamento contábil sobre os ativos e passivos em moeda estrangeira foram questionados em 2001 e 2002, quando ocorreu uma grande volatilidade nas cotações do dólar no Brasil, com movimentos ascendentes e descendentes bastante acentuados.

Baseados na necessidade de se manter atributos contábeis como confiabilidade, compreensibilidade e comparabilidade, faz-se necessário um debate entre os profissionais da Contabilidade e seus usuários visando aprimoramentos nas informações contábeis.

O presente trabalho apresenta uma proposta que foi encaminhada ao IBRACON e, informalmente, à CVM em outubro de 2001, como uma alternativa ao diferimento da variação cambial permitido pelo Governo Federal e apresentado na ABRASCA em 2002 estando sua aplicabilidade sendo discutida.

\section{ESTRUTURA CONCEITUAL DA CONTABILIDADE:}

Segundo o Princípio da Competência, os Ativos e Passivos em Moeda Estrangeira devem ser contabilizados considerando a cotação na data do Balanço e as contrapartidas devem ser reconhecidas em resultado. Esse posicionamento está incluso no texto da Lei $6.404 / 76$ no artigo 184 , inciso II e na NBC T 7- Da Conversão da Moeda Estrangeira nas Demonstrações Contábeis, emitida em 19.09.2001 e aprovada pela resolução do Conselho Federal de Contabilidade $\mathrm{n}^{\circ} 912$ de 09.10.2001.

O lançamento contábil admite, de modo intrínseco, que a cotação do dólar na data do Balanço represente um valor que expresse efetivamente a paridade econômica em relação à moeda nacional.

Com o sistema de câmbio flutuante, porém, há uma mudança de lógica. Em momentos específicos, como pôde ser constatado no Brasil em 2001/ 2002, ocorrem elevações e diminuições temporárias denominadas overshootings e undershootings. As empresas que têm ativos e passivos em moeda estrangeira são obrigadas a reconhecer flutuações que deverão ser posteriormente revertidas. No caso da empresa que possui ativos em moeda estrangeira, esta contabiliza um acréscimo patrimonial que pode não se concretizar, acarretando pagamentos sobre resultados não realizados. Reconhecendo essa problemática nas Demonstrações Contábeis de 30.09.2002, três importantes instituições financeiras brasileiras adotaram um valor diferenciado para o dólar. 0 Bradesco utilizou o dólar a $\mathrm{R} \$ 2,88$, o Unibanco adotou o valor de $R \$ 3,20$ e o Itaú considerou $R \$ 3,50$. O posicionamento é aceitável, inclusive pela Convenção do Conservadorismo, entretanto deve ser reconhecido que houve uma perda na comparabilidade entre as Demonstrações Contábeis dessas instituições financeiras entre si e com as outras que mantiveram o dólar PTAX de $R \$ 3,89$. 


\section{COTAÇÃO DO DÓLAR}

Em seguida apresentamos o valor do dólar venda PTAX no final de cada mês dezembro de 2000 a dezembro de 2002 e o gráfico com estes valores indicando o movimento de elevação e redução.

Tabela 1 - Valor do Dolár (Venda PTAX)

\begin{tabular}{|lrr|}
\hline Cotação do Dólar & & $\mathbf{2 0 0 1}$ \\
& $\mathbf{2 0 0 2}$ \\
DEZ & $\mathbf{1 , 9 5 5 4}$ & 2,3204 \\
\hline JAN & 1,9711 & 2,4183 \\
\hline FEV & 2,0452 & 2,3482 \\
\hline MAR & 2,1616 & 2,3236 \\
\hline ABR & 2,1847 & 2,3625 \\
\hline MAIO & 2,3600 & 2,5220 \\
\hline JUN & 2,3049 & 2,8444 \\
\hline JUL & 2,4313 & 3,4285 \\
\hline AGO & 2,5517 & 3,0223 \\
\hline SET & 2,6713 & 3,8949 \\
\hline OUT & 2,7071 & 3,6450 \\
\hline NOV & 2,5287 & 3,6356 \\
\hline DEZ & 2,3204 & 3,5333 \\
\hline
\end{tabular}

GRÁFICO 1 - DÓLAR 2001

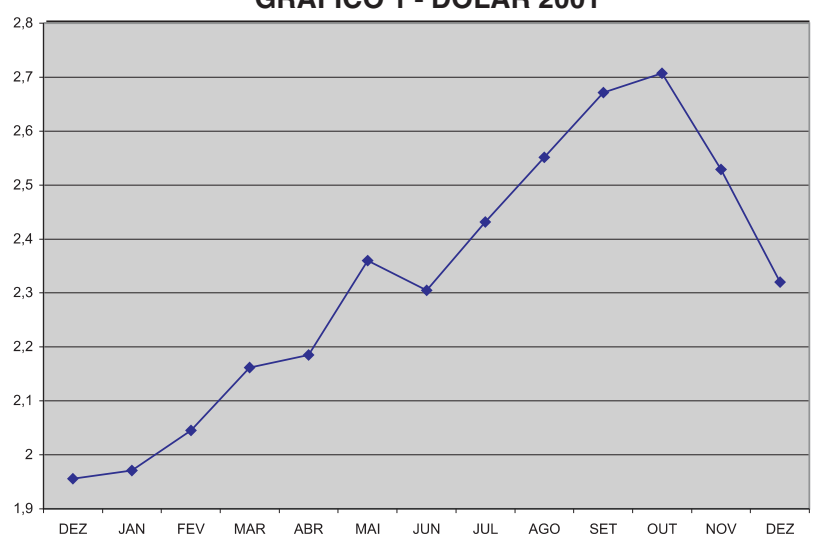

GRÁFICO_2- DÓLAR 2002

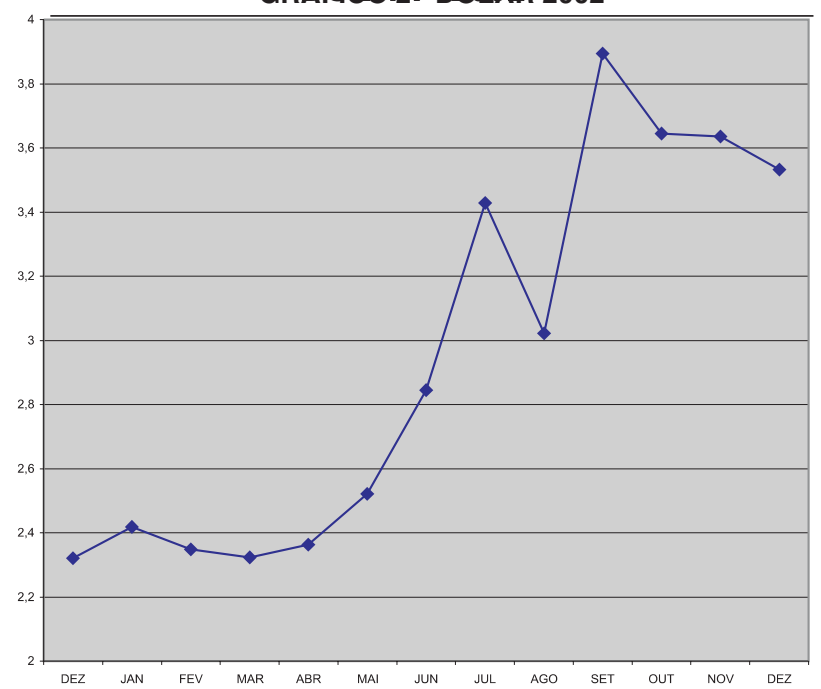

\section{PROPOSTA: VALOR EQUALIZADO DO DÓLAR (FAIR VALUE)}

Uma alternativa diferenciada que poderia ser adotada para os ativos e passivos de longo prazo (não hedgeados) seria atualizá-los por um valor que representasse a perspectiva do valor efetivo do dólar na data da liquidação. Dessa forma, as empresas não iriam efetuar a atualização pela taxa de fechamento a cada período, pois este valor é sujeito a oscilações de caráter temporário. A proposta é utilizar uma cotação que se aproxima de um "Valor Justo" do dólar de acordo com a teoria econômica. No momento da transferência do item patrimonial para o curto prazo, a avaliação passaria a ser realizada pelo dólar da taxa de fechamento.

\section{1."Dólar Justo"}

\subsubsection{Fundamentação}

Na definição do parâmetro foram utilizados conceitos provenientes da Teoria econômica da Paridade Cambial e utilizada a experiência do Banco Mundial. Esta instituição reconhece que o desequilíbrio dos valores das diversas moedas em determinados momentos é um fato econômico plenamente possível.Em decorrência, adota para a comparabilidade de indicadores econômicos entre os diversos países um conceito alternativo denominado Purchasing Power Parity Conversion. A Ciência Econômica considera como um parâmetro relevante para estimar o equilíbrio cambial o valor derivado da Teoria de Paridade do Poder de Compra, instituída pelo economista sueco Gustav Cassel que considera que, no médio prazo, a cotação das moedas deve refletir o efeito das diferenças entre as taxas de inflação entre os países.

\subsubsection{Cálculo}

A fórmula de cálculo para 31.12.2002 tem como valor-base o montante apurado de acordo com o PPP (Purchasing Power Parity), calculado pelo Banco Mundial para Dezembro de 2000 e disponível no site da referida instituição no endereço www.worldbank.org. Essa data representa a publicação mais recente disponível. 
O parâmetro calculado pelo Banco Mundial indica que o valor do dólar nessa data deveria ser de $\mathrm{R} \$ 2,25$. Esse valor é atualizado pelo IGPM até 31.12.2002 e descontado pela taxa de inflação norte-americana do período, que corresponde ao CPI- Consumer Price Index - All Urban Consumers, disponível no site www.bls.gov, Bureau de Labor Statistics.

Os parâmetros são os seguintes:

\begin{tabular}{|l|l|}
\hline IGPM 2001: & $10,38 \%$ \\
IGPM 2002: & $25,31 \%$ \\
Inflação norte-americana: & $6 \%$ (entre 31.12 .2000 e 31.12.2002) \\
\hline
\end{tabular}

Observação: No mês de Dezembro de 2002 foi repetida a mesma taxa do mês de Novembro de 2002 pois a informação ainda não estava disponível. Esse fato não gera efeitos materiais.

Efetuando o cálculo, obtém-se o fator de Correção equivalente(1) :

$(1,1038 \times 1,2531) / 1,06=1,304879$

O valor do "Dólar Justo" correspondente a 31.12.2000 calculado de acordo com o Banco Mundial é de $R \$ 2,25(2)$.

O valor estimado do "Dólar Justo" para 31.12.2002 é obtido através da seguinte multiplicação:

$$
1,304879(1) \times 2,25(2)=2,9359
$$

O valor efetivo do dólar PTAX nessa data é $R \$ 3,5333$, que corresponde a uma variação de $20,35 \%$. É importante afirmar que essa diferença, em Julho de 2002, ultrapassava a 50\%.

Através da evidenciação da fórmula de cálculo utilizada, verifica-se que o processo de apuração do valor do Dólar Justo pode ser considerado objetivo. Visando a que não existam dúvidas ou discordância quanto ao valor encontrado, faz-se necessário que o cálculo seja efetuado por uma entidade reconhecida e amplamente divulgado.

\subsubsection{Aplicação}

\section{a) Evidenciação como Notas Explicativas}

A proposição debatida por diversos profissionais da Contabilidade na reunião promovida pela CANC - Comissão de Auditoria e Normas Contábeis da ABRASCA, que contou com a participação do Prof. Eliseu Martins, consiste em a empresa apresentar uma Nota Explicativa indicando qual seria o resultado, o ativo, o passivo e o patrimônio líquido caso o Dólar Justo estivesse sendo adotado.

Esse posicionamento poderia permitir uma assimilação gradativa deste conceito.

b) Incorporado às Demonstrações Contábeis:

Foi proposto, ainda o reconhecimento nas Demonstrações Contábeis como um tratamento contábil definitivo.

Nesse sentido, é sugerido que as empresas brasileiras passem a corrigir os ativos e passivos de longo prazo com cláusula de variação cambial de acordo com a Teoria de Paridade do Poder de Compra, ou seja, o valor seria atualizado pela variação do IGPM descontado pela taxa de inflação norte-americana. Os itens patrimoniais seriam atualizados até 0 limite do "Dólar Justo".

A diferença em relação ao valor nominal poderia ter um dos seguintes tratamentos:

- evidenciação em notas explicativas;

- contabilização como redutora do passivo;

- contabilização como ajuste ao patrimônio líquido, aplicando um conceito semelhante ao utilizado nas normas internacionais de contabilidade.

$\mathrm{Na}$ data da implantação do método poderiam ocorrer duas possibilidades. Na primeira seria utilizado o próprio valor do "Dólar Justo". Outra alternativa, considerando a característica da praticabilidade, seria utilizar como referência o valor do Dólar Comercial de Venda. Se a proposta fosse aplicada no dia 31.12.2002, por exemplo, o valor de $\mathrm{R} \$ 3,5333$ constituiria o parâmetro de partida. Nessa hipótese, haveria uma margem de segurança de $20,35 \%$.

O reconhecimento do dólar efetivo no resultado ocorreria, portanto, na transferência para o curto prazo.

Esse tratamento deveria ter uma evidenciação plena pelas empresas. Em relação ao Parecer dos Auditores Independentes, propomos que o IBRACON determine a inclusão de um Parágrafo de ênfase. 


\section{EFEITOS NAS DEMONSTRAÇÕES CONTÁBEIS DE 31.12 .2002}

\section{Exemplo Simplificado:}

Em seguida será efetuada a exemplificação, considerando a utilização da metodologia em questão nas Demonstrações Contábeis de 31.12.2002:

Balanço Inicial da empresa - 31.12.2001

\begin{tabular}{|llll|}
\hline Terrenos & Financiamentos em Moeda Estrangeira* & $2.320,40$ \\
\hline
\end{tabular}

*Financiamento equivalente a 1.000 dólares

Forma Tradicional - Legislação Societária

Balanço em 31.12.2002

\begin{tabular}{|cccc|}
\hline Terrenos & $2.320,40$ & $\begin{array}{l}\text { Financiamentos em Moeda Estrangeira* } \\
\text { Prejuízos Acumulados }\end{array}$ & $\begin{array}{r}3.533,30 \\
(1.212,90)\end{array}$ \\
\cline { 2 - 4 } Terrenos & $2.320,40$ & & $2.320,40$ \\
\hline
\end{tabular}

*O Passivo foi atualizado considerando o valor do dólar de $\mathrm{R} \$ 3,5333$.

Demonstração do Resultado - Período 01.01.2002 a 31.12.2002

$\begin{array}{ll}\text { Variação Cambial Passiva } & (1.212,90) \\ \text { Prejuízo Líquido } & (1.212,90)\end{array}$

Nessa forma tradicional de contabilização, o valor do Passivo e do prejuízo estariam superavaliados.

Aplicação do conceito de "Dólar Justo"

\section{A) Modelo de Nota Explicativa}

Se a empresa adotasse o conceito de Dólar Justo, os seguintes saldos seriam obtidos:

Financiamentos

$R \$ 2.935,90$

Prejuízo

$\mathrm{R} \$(615,50)$

Patrimônio Líquido

$\mathrm{R} \$(615,50)$

B) Proposta considerando a contabilização do "Dólar Justo" nas Demonstrações de 31.12.2002

O tratamento contábil poderia ser realizado considerando três hipóteses apresentadas a seguir:
Hipótese A- Evidenciação da diferença entre o "Dólar Justo" e o Dólar efetivo como Nota Explicativa

Em 31.12. 2002, o Passivo seria atualizado de acordo com a variação do IGPM descontado pela taxa de inflação norte-americana. O lançamento seria o seguinte:

D- Variação Cambial Passiva

615,50

C- Financiamentos

615,50

Demonstração do Resultado- Período 01.01.2002 a 31.12.2002:

Variação Cambial Passiva

Prejuízo Líquido

$(615,50)$

$\overline{(615,50)}$ 
O Balanço Patrimonial proposto seria o seguinte:

\begin{tabular}{|cllr|}
\hline Terrenos & $2.320,40$ & Financiamentos em Moeda Estrangeira & $2.935,90$ \\
& & Prejuízos Acumulados & $(615,50)$ \\
Terrenos & $\overline{2.320,40}$ & & $\frac{2.320,40}{2.40}$ \\
\hline
\end{tabular}

Em Nota Explicativa seria evidenciado que o valor do Passivo, de acordo com a taxa de câmbio de fechamento, seria $\mathrm{R} \$ 3.533,30$.

Hipótese B - Reconhecimento da diferença entre o "Dólar Justo" e o Dólar efetivo como conta redutora do Passivo

Em 31.12.2002, o Passivo seria atualizado de acordo com o dólar efetivo. A diferença entre esse montante e o valor do Passivo corrigido pelo IGPM descontado pela taxa de inflação norte-americana seria considerado como uma conta redutora do Passivo.
O seguinte lançamento contábil seria realizado:

D- Variação Cambial Passiva $\quad 615,50$

D- Redutora do Passivo $\quad 597,40$

C- Financiamentos $\quad 1.212,90$

Demonstração do Resultado- Período 01.01.2002 a 31.12.2002:

Variação Cambial Passiva

$(615,50)$

Prejuízo Líquido

O Balanço Patrimonial proposto seria o seguinte:

\begin{tabular}{|c|c|c|c|}
\hline \multirow[t]{5}{*}{ Terrenos } & $2.320,40$ & Financiamentos em Moeda Estrangeira & $3.533,30$ \\
\hline & & Redutora do Passivo & $(597,40)$ \\
\hline & & Passivo líquido & $2.935,90$ \\
\hline & & Prejuízos Acumulados & $(615,50)$ \\
\hline & $2.320,40$ & & $2.320,40$ \\
\hline
\end{tabular}

Hipótese C - Reconhecimento da diferença entre o "Dólar Justo "e o Dólar efetivo como ajuste do Patrimônio Líquido

Em 30.09.2002, o Passivo seria atualizado de acordo com o dólar efetivo. A diferença entre esse montante e o valor do Passivo corrigido pelo IGPM descontado pela taxa de inflação norte-americana seria considerado como um ajuste direto ao Patrimônio Líquido.
O seguinte lançamento contábil seria realizado:

D- Variação Cambial Passiva $\quad 615,50$

C- Financiamentos $\quad 615,50$

Demonstração do Resultado - Período 01.01.2002 a 31.12.2002

\begin{tabular}{|ll|}
\hline Variação cambial Passiva & $(615,50)$ \\
Prejuízo Líquido & $(615,50)$ \\
\hline
\end{tabular}

O Balanço Patrimonial proposto seria o seguinte:

\begin{tabular}{|lllr|}
\hline Terrenos & $2.320,40$ & Financiamentos em Moeda Estrangeira & $3.533,30$ \\
& & Ajuste do Patrimônio Líquido & $(597,40)$ \\
& Prejuízos Acumulados & $(615,50)$ \\
& & & $\frac{(2.320,40}{2.320,40}$
\end{tabular}

Essa última alternativa teria a desvantagem de evidenciar o Passivo por um valor superior ao que se estima ser o saldo na data da liquidação efetiva. 


\section{AVALIAÇÃO PRÁTICA DA PROPOSTA}

O movimento do dólar nos anos de 2001, 2002 e início de 2003 incentiva a presente proposta.

As Demonstrações Contábeis do terceiro trimestre de 2002 indicaram para muitas empresas com obrigações de longo prazo em moeda estrangeira um prejuízo gigantesco que posteriormente foi revertido. A Aracruz, no balanço do $3^{\circ}$ trimestre, por exemplo, registrou um prejuízo acumulado no ano de $\mathrm{R} \$ 161,7$ milhões. A administração da companhia declarou ao Jornal O Globo em 11/10/02 que o prejuízo seria "meramente contábil" . Em dólar, a Aracruz acumulou lucro de US\$ 144 milhões entre janeiro e setembro.

O atual tratamento contábil gera, ainda, dificuldades adicionais para as empresas brasileiras, como por exemplo a incidência de PIS e COFINS no momento da reversão da taxa de câmbio sobre os Passivos em moeda estrangeira e a tributação das operações de hedge. Um aspecto problemático decorre de o valor do dólar sofrer oscilações positivas e negativas e depois retornaram ao mesmo patamar. Essa diferença é, a rigor, tributada no caso do acréscimo para os ativos, e diminuição do dólar para os passivos. Esse fato pode ter um efeito cíclico perverso.

No início de 2003 tivemos o movimento inverso do dólar sinalizando novamente uma distorção na qualidade das Demonstrações Contábeis, consideran- do uma visão de longo prazo. Com a redução do valor do dólar, empresas altamente endividadas em moeda estrangeira com uma situação financeira difícil passam a apresentar lucro, enquanto empresas com ativos em dólares em situação de liquidez confortável passam a apresentar elevados prejuízos. Novamente, a informação contábil estará sujeita a críticas.

Outro fator relevante a ser considerado é o de que, em momentos de grande incerteza, quando a cotação do dólar atinge os valores máximos, existe um incentivo às empresas que possuem obrigações em moeda estrangeira adquirirem dólares ou estruturarem operações com instrumentos financeiros para proteção visando reduzir a sua exposição cambial que será reconhecida de forma negativa nas Demonstrações Contábeis. Em determinados momentos, verifica-se que essa proteção poderia não ser necessária para empresas com obrigações de longo prazo. Entretanto, houve um custo significativo para a empresa assim como para grande parcela da sociedade brasileira.

A flutuação da taxa de câmbio a que está sujeito o Brasil desde 2001 trouxe aos Contadores uma certeza: é necessário uma reflexão. A inércia poderá custar a falta de valorização da informação contábil e, em conseqüência, dos profissionais da área.

Com todas essas variáveis atuando no campo econômico, a Contabilidade não deve evitar de reproduzir a realidade em que está inserida. 


\section{CONCLUSÕES}

O conteúdo informacional das Demonstrações Contábeis constitui o grande canal de comunicação entre as empresas e os investidores que financiam a atividade empresarial. A partir da adoção do câmbio flutuante, a qualidade informacional da Contabilidade das empresas que possuem ativos e passivos em moeda estrangeira é distorcida em determinados momentos pelos acréscimos ou decréscimos temporários nas cotações.

A utilidade das Demonstrações Contábeis no terceiro trimestre de cada ano foi questionada.

Tal fato nos leva a propor um debate quanto à necessidade de modificações.

A proposta da adoção do "Dólar Justo"de acordo com a Teoria da Paridade Cambial, representa uma alternativa para que a Contabilidade possa enfrentar este desafio.

A sua concepção é prática e objetiva e pode ampliar a utilidade das Demonstrações Contábeis. A proposta de se iniciar pela evidenciação é um bom caminho. A possibilidade do reconhecimento futuro nas próprias Demonstrações Contábeis também deveria ser debatida.

Essa proposta, além de poder propiciar bene- fícios para as empresas e para os usuários, pode ser de grande utilidade para o Brasil, uma vez que enseja uma menor procura por dólares ou hedge nos momentos de maior incerteza. Esse aspecto pode ser analisado à luz da Abordagem Macroeconômica da Teoria da Contabilidade, pois pode contribuir para o objetivo de reduzir as grandes oscilações da moeda estrangeira ao mensurar resultados relativamente mais estáveis de período a período.

A avaliação da consequência da mudança da política cambial na posição patrimonial, bem como sua relevância e resultados futuros, deve ser feita de modo criterioso para que não ocorra qualquer ameaça à continuidade da totalidade ou de parte das atividades da entidade.

Julgamos que o debate dessa proposta possa propiciar a abertura de outras idéias por outros pesquisadores da área.

Gostaríamos de ter a consciência de que, se ao final do debate com a classe for concluído que nada pode ser alterado, que pelo menos essa conclusão seja fruto de uma reflexão dos estudiosos da Contabilidade, não da determinação de se manter imutável algo, mesmo quando evidenciada sua inadequação à realidade. 


\section{REFERÊNCIAS BIBLIOGRÁFICAS}

ALMEIDA, Marcelo Cavalcanti, Contabilidade Avançada, São Paulo, Atlas, 1997.

BEAMS, Floyd A, BROZOVSKY, John \& SHOULDERS, Craig D. Advanced Accounting. $7^{\mathrm{a}}$ Ed.Prentice Hall, New Jersey, 1999

DELANEY, Patrick R., EPSTEIN James R.ADLER, Barry \& FORAN, Michael F., GAAP2000- Interpretation and Application of Generally Accepted Accounting Principles, John Willey \& Sons, New York, 1999

HENDRIKSEN, Eldon S. e VAN BREDA Michael F., Accounting Theory, Richard D.Irwinn, Homewood 1992

IUDICIBUS, Sérgio. Teoria da Contabilidade Ed. Atlas. SP. $1^{\circ} \mathrm{Ed} .1980$

MARTINS Eliseu. Variações Cambiais, Contabilidade e Fisco. Boletim 8. Temática Contábil Boletim IOB 2000

A posição do Conselho Federal de Contabilidade com relação à atualização monetária dos balanços: decepção! Boletins 15 e 16 , Temática Contábil Boletim IOB 2002.

RADEBAUGH Lee H., e GRAY, Sidnei J., International Accounting and Multinational Enterprises, John Wiley \& Sons, New York, 4ª ed, 1997

SANTOS, Ariovaldo dos - Aspectos da Conversão de Demonstrações Financeiras em Moeda Estrangeira, Dissertação de Mestrado, São Paulo, FEA-USP, 1980.

SANTOS, Ariovaldo dos - Alguns efeitos da utilização de índices inadequados na correção dos Balanços de empresas estrangeiras no Brasil, Tese de Doutoramento, São Paulo, FEA-USP, 1993

SIMONSEN, Mario Henrique. Textos Escolhidos. Ed.FGV, RJ $1{ }^{\circ}$ Ed. 2002

SZUSTER, Fortunee Comportamento do Mercado de Ações frente ao Diferimento Cambial de Março de 1999- Um Estudo Exploratório. Dissertação de Mestrado UERJ.RJ.2002 